\title{
Characterization of Zero-Valent Iron Nanoparticles Functionalized with a Biomarker Peptide
}

\author{
Indry Milena Saavedra Gaona ${ }^{a}$, Yehidi Medina Castillo ${ }^{b, d}$, Mónica Losada-Barragán ${ }^{b}$, \\ Karina Vargas Sanchez $z^{c}$, Javier Rincón ${ }^{d}$, Carlos Arturo Parra Vargas ${ }^{a}$, Daniel Llamosa Pérez ${ }^{d *}$ (i) \\ ${ }^{a}$ Universidad Pedagógica y Tecnológica de Colombia, Escuela de Física, Grupo Física de Materiales, \\ Avenida Central del Norte, 39-115, 150003, Tunja, Boyacá, Colombia. \\ ${ }^{b}$ Universidad Antonio Nariño, Facultad de Ciencias, Biología celular y funcional e Ingeniería de \\ moléculas, Sede Bogotá D. C., Colombia. \\ ${ }^{c}$ Universidad de los Andes, Escuela de Medicina, Bogotá, Colombia. \\ ${ }^{d}$ Universidad Antonio Nariño, Facultad de Ciencias, Grupo Investigación fundamental y aplicada en \\ Materiales, Sede Bogotá D. C., Colombia.
}

Received: December 30, 2020; Revised: May 07, 2021; Accepted: June 24, 2021

\begin{abstract}
The identification of peptides that can be coupled to magnetic nanoparticles and be directed against specific receptors has been developed and applied intensively in various biomedical applications, such as magnetic resonance imaging (MRI), to diagnose neurodegenerative diseases. This work describes the properties of magnetic zero-valent iron (nZVI) nanoparticles coated with silica and subsequently decorated with a peptide as a biomarker of neuroinflammation. The synthesized nanostructured compounds were systematically characterized by XRD, SEM, AFM, DLS, FTIR and VSM techniques. Biotin-Streptavin-HRP system was carried out to confirm the peptide's anchoring to the surface of the nanoparticles. The results showed that this nanostructured compound is an excellent candidate as a contrast agent capable of being used in magnetic resonance imaging, which would optimize the diagnosis of neuroinflammatory lesions compared to current contrast media.
\end{abstract}

Keywords: Zero-valent iron, magnetic composite nanoparticles, MRI, peptide.

\section{Introduction}

Biocompatible magnetic nanoparticles (MNP) have a high potential in biomedical applications such as in cellular therapy, hyperthermia, or as a contrast agent for magnetic resonance imaging (MRI) $)^{1,2,3,4,5}$. The MNP can have sizes from tens to a few hundreds of $\mathrm{nm}$; these have improved the image quality of tissues analyzed by MRI. They can decrease the $\mathrm{T} 1$ and $\mathrm{T} 2$ relaxation times and improve the tissue contrast on MRI.

Recent advances in the design of specific biomarkers for brain imaging have improved clinic diagnostics using MRI. These improvements have allowed the characterization of different phenotypes of neurodegenerative disorders by detecting structural and functional changes ${ }^{6,7}$. Current research is oriented to the design of biomarker probes using peptides and antibodies to detect and evaluate, in real-time, modifications, or molecular alterations in cell populations or tissues of interest ${ }^{8,9}$.

When using MNPs for biomedical applications, it is crucial to control the nanoparticles' oxidation because it could lead to a degradation of their magnetic properties ${ }^{10,11}$. To prevent the oxidation process, silica $\left(\mathrm{SiO}_{2}\right)$ is used as a protective coating material on iron oxide cores. $\mathrm{SiO}_{2}$ coating improves the MNP stability and gives a suitable surface for the coupling of specific biomarkers ${ }^{12,13,14}$.

*e-mail: dllamosa@uan.edu.co
This study was focused on the development of nanoscale zero-valent iron particles (nZVI) coated with silica $\left(\mathrm{Fe} @ \mathrm{SiO}_{2}\right)$ synthesized by acid hydrolysis of alkoxides and the anchoring of a biomarker peptide on its surface $\left(\mathrm{Fe} @ \mathrm{SiO}_{2} / \mathrm{Pe}\right)$ as potential candidates of contrast agent for MRI in diagnosing neuroinflammatory processes. The peptide used here was selected from an EAE animal model due to its specificity to target alterations in the blood-brain barrier (BBB) under neuroinflammatory conditions. The peptide labeling was also confirmed by in vitro assays in a brain vascular endothelial cell line (HCMEC/D3) under pro-inflammatory conditions ${ }^{15,16}$.

The nanoparticles were characterized by $\mathrm{X}$-ray diffraction (XRD), scanning electron microscopy (SEM), atomic force microscopy (AFM), dynamic light scattering (DLS), Fourier transform infrared spectroscopy (FTIR) and vibrating sample magnetometry (VSM). A biotin-streptavidin-HRP system was used to confirm the conjugation of the peptide to the nZVI surface.

\section{Experimental}

\subsection{Chemical and reagents}

Zero-valent iron nanoparticles (nZVI) Nanofer $25 \mathrm{~S}$ were purchased from NANOIRON Ltd. (CAS No.: 7439-89-6). Ethanol $\left(\mathrm{C}_{2} \mathrm{H}_{5} \mathrm{OH}\right)(\mathrm{CAS}$ No.: 64-17-5), tetraethylorthosilicate (TEOS) (CAS No.: 78-10-4), methyltriethoxysilane 
(MTES) (CAS No.: 2031-67-6), acetic Acid ( $\left.\mathrm{CH}_{3} \mathrm{COOH}\right)$ (No.: 200-580-7) were obtained from Merck. Potassium Chloride (KCl) (CAS No.: 7447 -40-7) and monopotassium phosphate $\left(\mathrm{KH}_{2} \mathrm{PO}_{4}\right)(\mathrm{CAS}$ No.: $7778-77-0)$ were obtained from Sigma. Dibasic phosphate $\left(\mathrm{Na}_{2} \mathrm{HPO}_{4}\right)$ was purchased from Acros (CAS No.: 10039-32-4). The biotinylated peptide (TPMMPETSQRFK) was synthesized by Genscript.

\subsection{Silica surface preparation and functionalization}

The nZVIs were protected with $\mathrm{SiO}_{2}$ layer, obtaining $\mathrm{Fe} @ \mathrm{SiO}_{2}$ nanoparticles. The process of coating the magnetic nanoparticles with $\mathrm{SiO}_{2}$ was carried out by means of the synthesis of acid hydrolysis of alkoxides ${ }^{17,18}$. The nanoparticles were dispersed in ethanol to functionalize the surface, dried in an oven at atmospheric pressure. The resulting powder was dispersed in phosphate-buffered saline solution (PBS) and mixed with the biotinylated peptide $(\mathrm{Pe})$. The nZVIs were re-dispersed in ultrasound for $3 \mathrm{~s}$, obtaining the $\mathrm{Fe} @ \mathrm{SiO}_{2} / \mathrm{Pe}$ sample (Figure 1). Direct ultrasound transfer more energy to the nZVI, allowing more porous samples, which would imply greater anchoring of the peptide and particle size control.

\subsection{Characterization of $n Z V I$}

To determine the crystalline phases, XRD were taken at room temperature. The XRD pattern was acquired with a Panalytical X'pert PRO-MPD equipment with an Ultrafast $\mathrm{X}^{\prime}$ Celerator detector in Bragg-Brentano geometry, using Cobalt $\mathrm{CoK}_{\alpha}$ radiation $(\lambda=1.7890 \AA) 15^{\circ}$ to $90^{\circ} 2 \theta$ with a step of $0.0263^{\circ}$ and a capture time of $100 \mathrm{~s}$. The XRD patterns were analyzed with the General Structure Analysis System (GSAS) software. The morphological properties of the $\mathrm{Fe} @ \mathrm{SiO}_{2}$ nanoparticles were evaluated by means of scanning electron microscopy (SEM) with an energy dispersive spectrometer (EDS) in a Tescan Lyra 3; for this case, a carbon tape substrate was used.

To identify the nanoparticles height and size distribution, AFM was employed using 30 mg of Fe@SiO and $\mathrm{Fe} @ \mathrm{SiO}_{2} / \mathrm{Pe}$. Mica was used as a substrate. The samples were analyzed in an Asylum Research microscope, model MFP-3D-BI. DLS technique was applied to determine the hydrodynamic diameters distribution. $30 \mathrm{mg}$ of $\mathrm{Fe}$ and $\mathrm{Fe} @ \mathrm{SiO}_{2}$ nanoparticles dispersed in $5 \mathrm{~mL}$ of $\mathrm{H}_{2} \mathrm{O}$ was used. DLS measurements were performed with the Malvern Zetasizer Nano ZS equipment, model ZEN3600. The hydrodynamic diameter and the polydispersity index (PdI) were obtained from the autocorrelation fit of the data. The functional groups of the nanoparticles were examined by FTIR, these studies were done using a Bruker FTIR spectrophotometer, model Alpha. The spectrum for the Fe and $\mathrm{Fe} @ \mathrm{SiO}_{2}$ nanoparticles was taken with a resolution of $2 \mathrm{~cm}^{-1}$ in the range of 500-4000 $\mathrm{cm}^{-1}$. The magnetic measurements were developed using the vibrating sample magnetometer (VSM) Quantum Design. The measures taken as a function of temperature were carried out in a temperature range of $50-300 \mathrm{~K}$ using the Zero Field Cooled-Field Cooled (ZFC-FC) mode. The value of $\mathrm{M}$ vs $\mathrm{H}$ was taken from -30 to $30 \mathrm{kOe}$ at $300 \mathrm{~K}$.

\subsection{Evaluation of peptide linkage with the Fe@ $\mathrm{SiO}_{2}$ nanoparticles}

The linkage between the biotinylated-peptide and the surface of the nZVIs was evaluated using a biotin-streptavidin-HRP system. Briefly, in a previously hydrated 96-well plate, each well was blocked with 5\% BSA/PBS for 2 hours at room temperature. The plate was washed three-times and the samples were added to each well. The evaluated samples included: (1) a negative control without nZVIs or peptide, (2) nZVIs without functionalization, (3) the biotinylated peptide, and (4) the functionalized nZVIs. The samples were incubated for 2 hours at room temperature, and later, each well was washed and incubated with streptavidin-HRP for 30 minutes at room temperature in the dark. After washing, the substrate $\left(1: 1 \mathrm{H}_{2} \mathrm{O}_{2}\right.$ :tetramethylbenzidine (TMB) ) was added and set for 30 minutes at room temperature, protected from light. The reaction was stopped with $1 \mathrm{M} \mathrm{H}_{2} \mathrm{SO}_{4}$. The absorbance was determined in an FC Multiskan ${ }^{\mathrm{TM}}$ microplate reader at $450 \mathrm{~nm}^{19,20}$.

\subsection{Statistics}

Statistical analysis of functionalized nanoparticles was performed using an unpaired Student's $t$-test (GraphPad Prism version 6). Statistical significance was accepted at $p<0.05$.

\section{Results and Discussion}

\subsection{Structural analysis}

The XRD patterns observed at room temperature for iron nanoparticles $\left(\mathrm{Fe} @ \mathrm{SiO}_{2}\right.$ ) coated with silica and iron nanoparticles coated and decorated with the biomarker peptide $\left(\mathrm{Fe} @ \mathrm{SiO}_{2} / \mathrm{Pe}\right)$ are shown in Figure 2. Peaks were

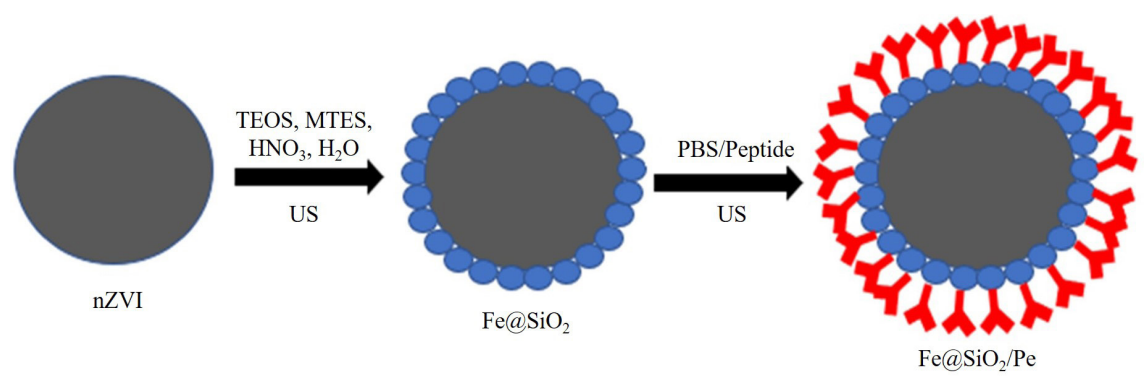

Figure 1. Scheme of the preparation of silica-coated zero-valent iron nanoparticles and subsequent functionalization of the peptide. US: Ultrasound. TEOS: tetraethylorthosilicate. MTES: methyltriethoxysilane. PBS: phosphate-buffer saline solution. 
identified at $2 \theta \approx 52.55^{\circ}(110)$ y $77.47^{\circ}(200)$ corresponding to Fe (JCPDS card no $65-4899)$, peaks at $2 \theta \approx 35.2^{\circ}(220)$, $41.53^{\circ}(311), 50.51^{\circ}(400), 67.34$ (511) and $74.25^{\circ}(440)$ correspond to $\mathrm{Fe}_{3} \mathrm{O}_{4}$ (JCPDS card no 19-0629) and peaks at $2 \theta \approx 37.02^{\circ}(620), 35.59^{\circ}(241)$ and $53.56^{\circ}$ (302) corresponding to silica $\mathrm{SiO}_{2}$ (ID: $\mathrm{mp}-558301$ ). The detailed analysis of XRD shown in the enlarged region of the main signal corresponds to the plane's orientation (110) in the range of $2 \theta \approx 52-53.2^{\circ}$ (inset of Figure 2 ). It is clearly seen that the full width at half maximum of the reflection peaks decreased after functionalizing the nanoparticles with the peptide, indicating growth in crystallinity or changes in crystalline pressure $^{21}$. The XRD peaks were identical even after the peptide functionalization procedure, indicating that the nZVI core's crystallinity is retained after coating, and only the intensity of the $\mathrm{Fe}_{3} \mathrm{O}_{4}$ peaks were slightly reduced, which was attributed to the formation of the amorphous silica layer ${ }^{2}$.

In the present study, we have adopted the Rietveld refinement technique using GSAS software in order to confirm the identified crystalline phases. The refined patterns are shown in Figure 3. The small values of the statistical adjustment parameters $\left(\chi^{2} \mathrm{y} R\left(\mathrm{~F}^{2}\right)\right)$ confirm the stability of the phases. According to the structural parameters obtained by the refinement of nanoparticles (Table 1), the phase

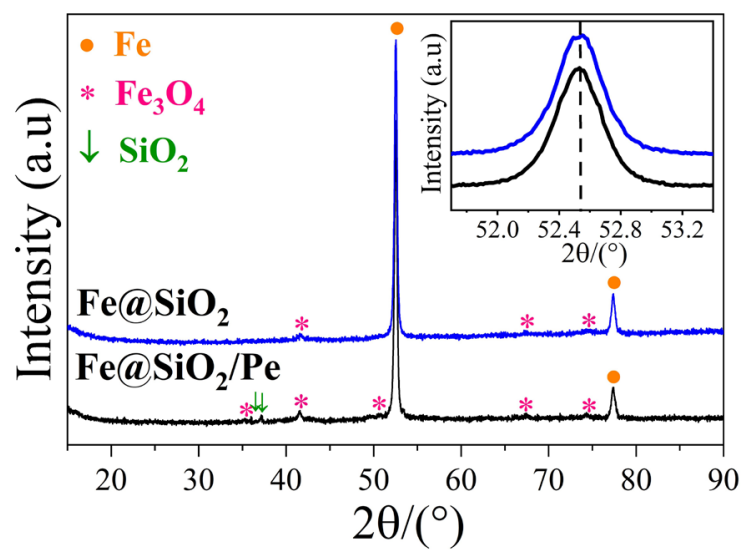

Figure 2. XRD diffraction pattern of $\mathrm{Fe} @ \mathrm{SiO}_{2}$ and $\mathrm{Fe} @ \mathrm{SiO}_{2} / \mathrm{Pe}$. Inset: Enlarged region of the main signal. percentage (W(\%)) of pure iron (ferrite) of the nanoparticles coated with silica corresponds to $99 \%$ compared to $90 \%$ of the nanoparticles coated with the peptide. This decrease in $\mathrm{W}(\%)$ of $\mathrm{Fe}$ is due to the oxidation of $\mathrm{Fe}$ and the coating of the ZVI nanofer with $\mathrm{SiO}_{2}$, clearly indicating that it is a very reactive absorbent, which is related to an increase in the surface area, indicating a greater probability of anchoring the peptide with nanoparticles ${ }^{22}$. The lattice parameters $(a$, $b$ and $c$ ) and cell volume change when the nanoparticles are functionalized with the peptide. The crystallite size of all samples was determined using the Scherrer equation $L=\kappa \lambda / \beta \cos \cos \theta$; where $\lambda$ is the wavelength of the incident beam, $\beta$ is the average height width, $\theta$ is the angle of reflection of the strongest signal, and $\kappa=0.9$ is a coefficient. Replacing the strongest signal's value corresponding to $2 \theta \approx 52.55^{\circ}$ with direction (110) in this equation and using the value of the average height width. According to the size of the crystallite, it can be determined that the nZVI are of a single domain, inferring that these nZVI present a superparamagnetic behavior since, at these sizes, the formation of domain walls that provide nZVI of multiple domains is energetically unfavorable ${ }^{23}$. The results showed

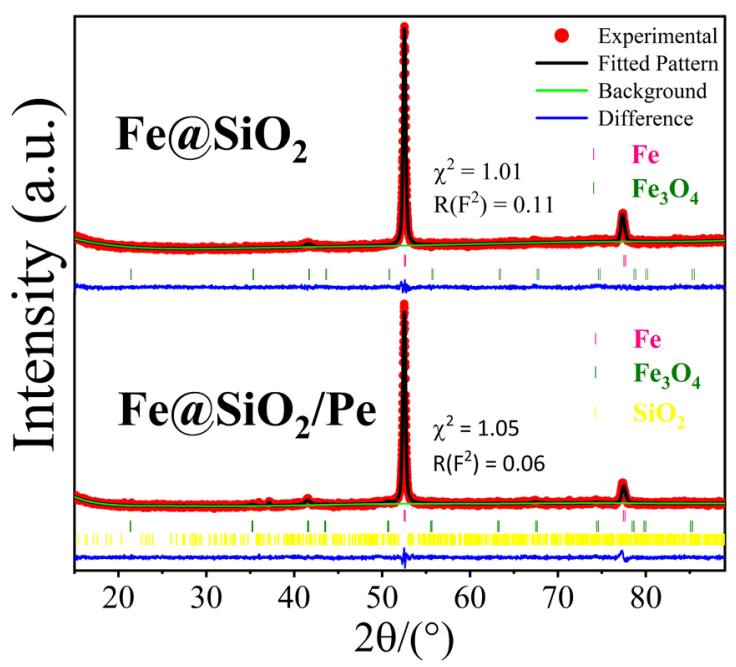

Figure 3. Rietveld refinement XRD patterns of $\mathrm{Fe} @ \mathrm{SiO}_{2}$ and $\mathrm{Fe} @ \mathrm{SiO}_{2} / \mathrm{Pe}$ systems.

Table 1. Structural parameters obtained by Rietveld refinement of nanoparticles.

\begin{tabular}{|c|c|c|c|c|c|c|}
\hline \multirow[t]{2}{*}{ Sample } & \multirow[t]{2}{*}{ Phase } & \multirow{2}{*}{$\begin{array}{c}\text { Phase content } \\
\text { W (\%) }\end{array}$} & \multirow[t]{2}{*}{ Space Group } & $\begin{array}{c}\text { Lattice } \\
\text { Parameter }(\AA)\end{array}$ & \multirow{2}{*}{$\begin{array}{l}\text { Cell Volume V } \\
\left(\AA^{3}\right)\end{array}$} & \multirow{2}{*}{$\begin{array}{l}\text { Crystallite size } \\
(\mathrm{nm})\end{array}$} \\
\hline & & & & $\mathrm{a}=\mathrm{b}=\mathrm{c}(\AA)$ & & \\
\hline \multirow{2}{*}{$\mathrm{Fe} @ \mathrm{SiO}_{2}$} & $\mathrm{Fe}$ & 99 & Im-3m (229) & $2.860(3)$ & $23.235(5)$ & \multirow{2}{*}{37.7} \\
\hline & $\mathrm{Fe}_{3} \mathrm{O}_{4}$ & 1 & $F d-3 m(227)$ & $8.350(2)$ & $582.247(8)$ & \\
\hline \multirow{5}{*}{$\mathrm{Fe} @ \mathrm{SiO}_{2} / \mathrm{Pe}$} & $\mathrm{Fe}$ & 90 & Im-3m (229) & $2.859(2)$ & 23. $389(1)$ & \multirow{5}{*}{77.4} \\
\hline & $\mathrm{Fe}_{3} \mathrm{O}_{4}$ & 8.5 & $F d-3 m(227)$ & $8.369(2)$ & $586.192(5)$ & \\
\hline & \multirow{3}{*}{$\mathrm{SiO}_{2}$} & \multirow{3}{*}{1.5} & \multirow{3}{*}{$\mathrm{C} 2 / \mathrm{m}(12)$} & $\mathrm{a}=18.258(4)$ & & \\
\hline & & & & $\mathrm{b}=13.348$ & $1894.519(5)$ & \\
\hline & & & & $\mathrm{c}=7.776(2)$ & & \\
\hline
\end{tabular}


an augment in the crystallite size when the nanoparticles are coated with the peptide (Table 1); such an increase is attributed to the inclusion of the amorphous silica layer and the rise in surface area. However, the size can be controlled by the amount of silica ${ }^{14}$.

A representative AFM image of the monodisperse $\mathrm{Fe} @ \mathrm{SiO}_{2}$ nanoparticles is displayed in Figure $4 \mathrm{a}$. The analysis of the height profile of the nanoparticles showed a size of $54 \pm 10 \mathrm{~nm}$ (Figure 4b). These results are similar to those reported by other works using nZVI Nanofer $25 \mathrm{~S}$ from NANOIRON Ltd ${ }^{24}$, it is observed that the NPs are dispersed and do not form aggregates, which is convenient for medical applications and especially to be functionalized. The similar contrast of each NP indicates that its height is close, which is important for its application, since having similar sizes will present similar magnetic properties ${ }^{25}$.

Figure 5 shows SEM micrographs at different magnifications, the size distribution and chemical composition of the NPs obtained after coating with $\mathrm{SiO}_{2}\left(\mathrm{Fe} @ \mathrm{SiO}_{2}\right)$. In Figure 5a it is observed that some
$\mathrm{Fe} @ \mathrm{SiO}_{2}$ nanoparticles are added; possibly this effect occurred due to the preparation of the sample for the measurement, where it was quickly dried in vacuum. It is possible to avoid agglomeration of the nZVI using a surfactant to negatively charging the surface of the nanoparticles ${ }^{6}$. These images were analyzed with the Image J program, obtaining the size distribution of the NPs. The data adjustment was carried out assuming a LogNormal distribution, where it was determined that the diameter of the NPs is $57 \pm 3.2 \mathrm{~nm}$. The EDS analysis of the $\mathrm{Fe} @ \mathrm{SiO}_{2}$ nanoparticles showed the peaks corresponding to $\mathrm{Fe}, \mathrm{O}$, and $\mathrm{Si}$ (Figure $5 \mathrm{~d}$ ). According to the composition table, the highest percentage corresponds to the ferrite (Fe) associated with the nanoparticle. The percentage of $\mathrm{Si}$ is due to the coating made to this nanoparticle.

With this size, NPs are viable for use in the early diagnosis and study in real-time of the mechanisms triggered under neuroinflammatory conditions since different studies have shown that nanoparticles of approximately $200 \mathrm{~nm}$ and $300 \mathrm{~nm}$ in size are capable of crossing the $\mathrm{BBB}^{26}$.
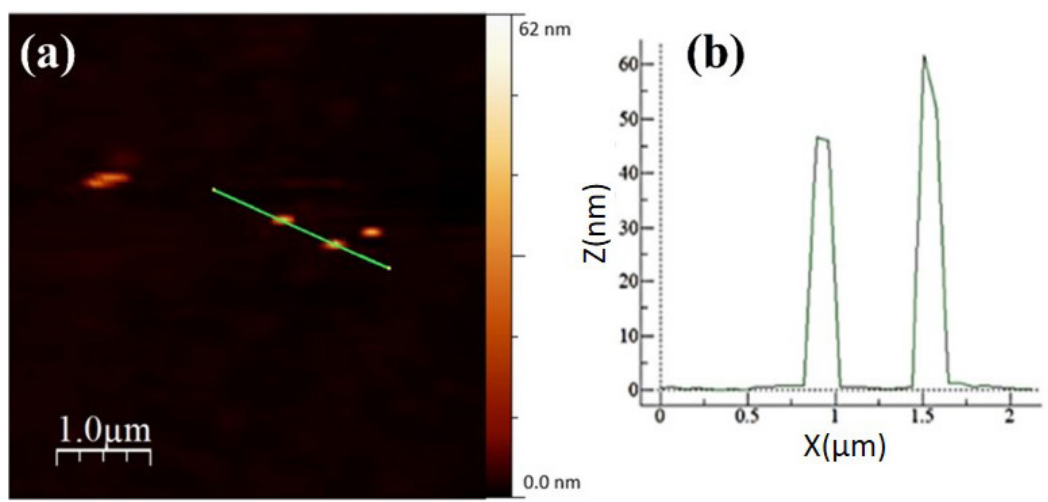

Figure 4. (a) $5 \times 5 \mu \mathrm{m}$ AFM image of $\mathrm{Fe} @ \mathrm{SiO}_{2}$ nanoparticles. The green line in the image indicates where the height profile was recorded. (b) Contour profile on the topography along the green line.
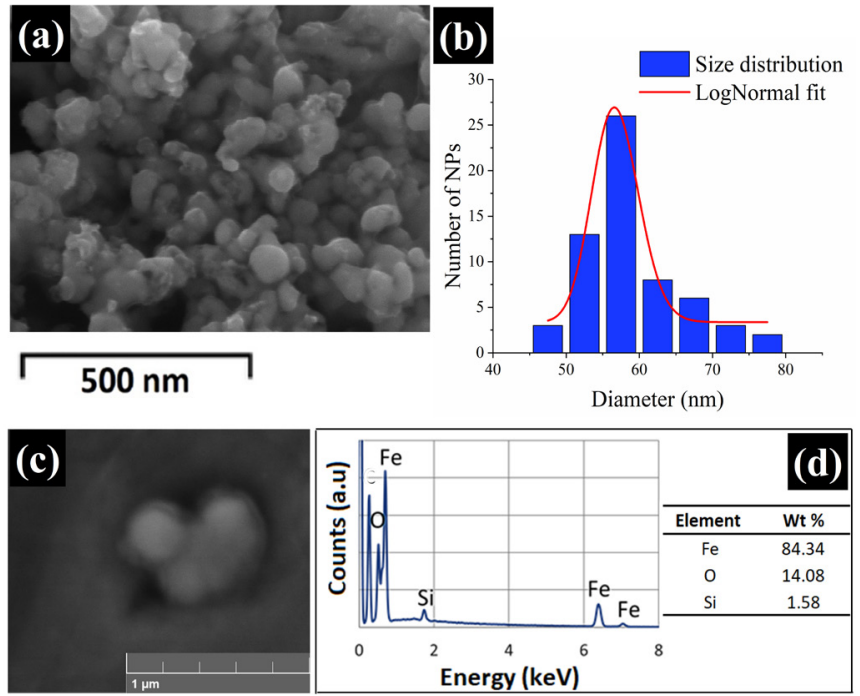

Figure 5. Representative SEM images of $\mathrm{Fe} @ \mathrm{SiO}_{2}$ nanoparticles. B) Size distribution of NPs (c) $602 \mathrm{kX}$ magnification of Fe@SiO nanoparticles. (d) EDS spectrum and representative elemental quantitative data of $\mathrm{Fe} @ \mathrm{SiO}_{2}$ nanoparticles. 
While SEM is useful to investigate size and morphology, DLS is important to quantify hydrodynamic diameter and polydispersity. This technique allows a more dynamic measurement as samples do not have to be dried. Figure 6a shows the hydrodynamic diameter of $\mathrm{Fe}$ and $\mathrm{Fe} @ \mathrm{SiO}_{2}$ nanoparticles measured by DLS. The average hydrodynamic size of the bare Fe nanoparticles is $100 \mathrm{~nm}$ and after coating the nanoparticles with $\mathrm{SiO}_{2}$, their average size increases to $122 \mathrm{~nm}$. This increased size evidenced the formation of the $\mathrm{SiO}_{2}$ coating on the nanoparticles of $\mathrm{Fe}^{27}$. The DLS generally shows a larger particle size compared to that in XRD, AFM and SEM, because the particle size is attributed to an average hydrodynamic size of agglomerated nanoparticles. It has been identified that the surface charge of the nanoparticles affects the measurement of the hydrodynamic size of the sample in colloidal form ${ }^{28,29}$. In contrast, the dry samples that are generally used for TEM analysis do not present this alteration. On the other hand, by increasing the number of hydrophilic groups on the surface, the probability of undesirable agglomeration among nanoparticles increases.

The polydispersity index (PDI) represents the distribution of size populations within a given sample. The numerical value of PDI ranges from 0.0 (for a perfectly uniform sample concerning particle size) to 1.0 (for a highly polydisperse sample with populations of multiple particle sizes). The Fe and $\mathrm{Fe} @ \mathrm{SiO}_{2}$ nanoparticles showed a $\mathrm{PDI}=0.15$, representing that these systems are highly monodisperse. Although the latest FDA edition of the "Industry Guide" for Pharmaceuticals emphasizes the importance of size and size distribution as "critical quality attributes", it does not mention the criteria for acceptable PDI. However, it has been established that for medical applications, a PDI of 0.3 and less is considered acceptable ${ }^{30}$.

Figure $6 \mathrm{~b}$ shows the FTIR spectra of the Fe (blue line) and $\mathrm{Fe} @ \mathrm{SiO}_{2}$ (red line) nanoparticles for comparison. There is a peak attributed to $\mathrm{Fe}-\mathrm{O}$ stretch vibrations at around $564 \mathrm{~cm}^{-1}$ in the spectrum of all the NPs synthesized. It proved the existence of $\mathrm{Fe}_{3} \mathrm{O}_{4}$ that was identified in the XRD of Figure 3. In the blue and red lines, the peak displays a slight deviation because of the influence of the bonds between $\mathrm{Fe}$ and $\mathrm{Si}$. The peak at $958 \mathrm{~cm}^{-1}$ is for $\mathrm{Si}-\mathrm{O}$ symmetric stretch, and the peak at $578 \mathrm{~cm}^{-1}$ is for Si-O-Fe. The peak of $1061 \mathrm{~cm}^{-1}$ in the red line essentially represents the characteristic Si-O-Si peak, and the peak of $970 \mathrm{~cm}^{-1}$ is the $\mathrm{Si}-\mathrm{O}$ bond stretch vibrations. The comparison of the blue line and red line indicates that the magnetic particles are successfully coated by $\mathrm{SiO}_{2}$ coating. And there are $\mathrm{H}-\mathrm{O}-\mathrm{H}$ groups and $\mathrm{O}-\mathrm{H}$ groups around the $\mathrm{SiO}_{2}$ surface suggested by the peak of $1621 \mathrm{~cm}^{-1}$ and $3000 \mathrm{~cm}^{-1}$. In all spectra, the absorption bands at $3650-3100 \mathrm{~cm}^{-1}$ correspond to $\mathrm{O}-\mathrm{H}$ stretching mode ${ }^{31}$.

Figure 7 shows the temperature dependence $(50 \mathrm{~K}<\mathrm{T}<350 \mathrm{~K})$ of the magnetization in an applied field $(\mathrm{H}=500 \mathrm{Oe})$ after a different cooling process in the ZFC and FC modes. In the ZFC process, the nanoparticles were cooled from room temperature to $50 \mathrm{~K}$ without applying an external magnetic field; then, the magnetization was recorded as a function of temperature with an applied field $(\mathrm{H}=500 \mathrm{Oe})$ during the heating process. In the case of field cooling (FC), the nanoparticles were cooled from 350 to $50 \mathrm{~K}$
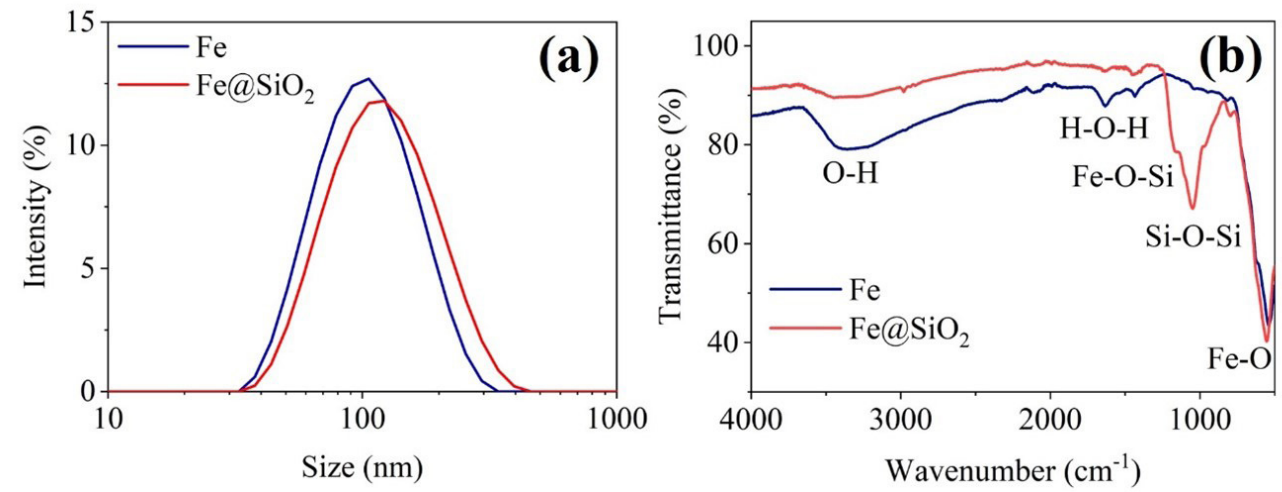

Figure 6. (a) Hydrodynamic diameter distribution by DLS and (b) FTIR spectra of Fe (blue line) and $\mathrm{Fe} @ \mathrm{SiO}_{2}$ (red line) nanoparticles.
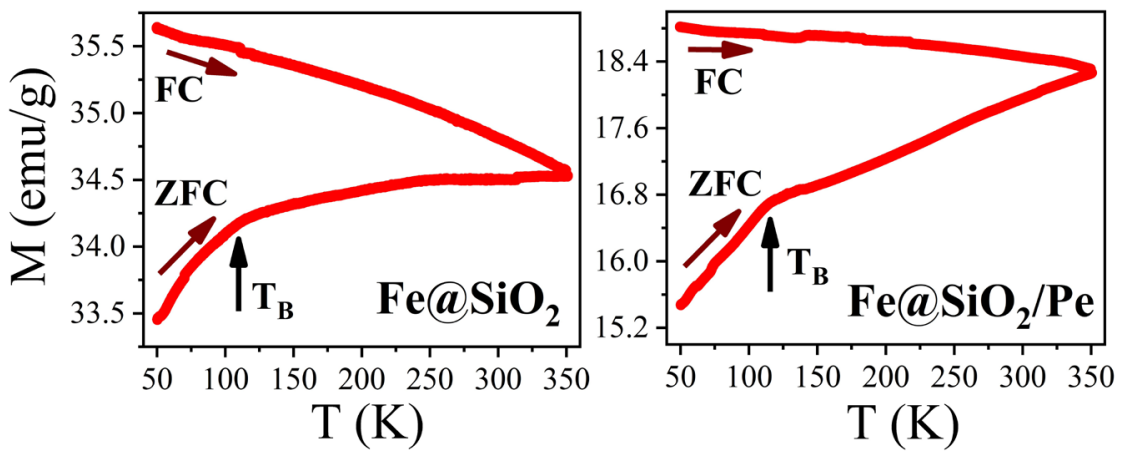

Figure 7. Temperature dependence of magnetization for field cooled (FC) and zero-field cooled (ZFC) nanoparticles under an applied field 500 Oe. 
in the presence of the external magnetic field $(\mathrm{H}=500 \mathrm{Oe})$, and the magnetization as a function of temperature was recorded with decreasing temperature, which favors the moment of individual particles to reorient themselves along the applied field at low temperature. More nanoparticles follow the applied magnetic field direction with an increase in temperature and reach the maximum at the blocking temperature $\left(\mathrm{T}_{\mathrm{B}}\right)^{32}$.

The $T_{B}$ is defined as the temperature above which a particle has enough relaxation time during the observation time to revert its moments to the orientation of the applied field $^{33}$. Therefore, the ZFC magnetization curves appear maximum at the blocking temperature $T_{B}$, at which the relaxation time is equal to the time scale of the magnetization measurements (Table 2). The substantial increase in ZFC magnetization below $\mathrm{T}_{\mathrm{B}}$ can be explained by some small particles contribution with a blocking temperature lower than $117.127 \mathrm{~K}$.

The ZFC-FC curves showed that as the temperature increases from 50 to $350 \mathrm{~K}$, the ZFC magnetization increases first and then decreases after reaching a maximum of $300 \mathrm{~K}$ (Figure 7). This result indicates that the synthesized nanoparticles show a paramagnetic behavior at room temperature. For synthesized systems, the FC magnetization increases as the temperature decreases to approximately $240 \mathrm{~K}$. Thus, the magnetization becomes almost constant as the temperature decreases to $50 \mathrm{~K}$, which is evident in the existence of a spin-glass surface structure ${ }^{34,35}$. The spin-glass behavior results from extensive interactions between particles, while the result that the spin-glass at the surface can be caused by the frozen disorganized surface spins ${ }^{36}$.

The hysteresis loops at room temperature varying the field from $-30 \mathrm{kOe}$ to $30 \mathrm{kOe}$ are shown in Figure 8. All curves showed coercivities and retentivity different from zero, providing a ferromagnetic shape ${ }^{5}$. The $\mathrm{Fe} @ \mathrm{SiO}_{2}$ and $\mathrm{Fe} @ \mathrm{SiO}_{2} / \mathrm{Pe}$ systems exhibited total saturation in a magnetic field of $20 \mathrm{kOe}$. As the external magnetic field increases, the magnetization first increases rapidly and then reach saturation. The saturation $\left(\mathrm{M}_{\mathrm{s}}\right)$, remanence $\left(\mathrm{M}_{\mathrm{r}}\right)$, and coercive fields $\left(\mathrm{H}_{\mathrm{c}}\right)$ magnetizations are shown in Table 2. The results showed a lower value for the nanoparticles functionalized with the peptide attributed to reducing the relative content of $\mathrm{Fe}$ when coating with the diamagnetic contribution $\mathrm{SiO}_{2}$. Compared to uncovered iron, the magnetization of saturation of the $\mathrm{Fe} @ \mathrm{SiO}_{2}$ nanoparticles increased due to the diamagnetic contribution of the silica shell resulting in a high mass fraction of the magnetic substance ${ }^{37}$. The magnetic properties obtained from $\mathrm{Fe} @ \mathrm{SiO}_{2}$ and $\mathrm{Fe} @ \mathrm{SiO}_{2} / \mathrm{Pe}$ allow them to be used as magnetically separable catalysts that can be easily separated from a reaction mixture when using relatively low fields and in biomedical applications ${ }^{38}$.

Table 2. Magnetic parameters, saturation magnetization $\left(\mathrm{M}_{\mathrm{s}}\right)$, coercivity $\left(\mathrm{H}_{\mathrm{c}}\right)$, and blocking temperature $\left(\mathrm{T}_{\mathrm{B}}\right)$ of the nZVIs.

\begin{tabular}{ccccc}
\hline Sample & $\begin{array}{c}\mathrm{M}_{\mathrm{s}}(\mathrm{emu} / \mathrm{g}) \\
300 \mathrm{~K}\end{array}$ & $\begin{array}{c}\mathrm{M}_{\mathrm{r}}(\mathrm{emu} / \mathrm{g}) \\
300 \mathrm{~K}\end{array}$ & $\begin{array}{c}\mathrm{H}_{\mathrm{c}}(\mathrm{Oe}) \\
300 \mathrm{~K}\end{array}$ & $\mathrm{~T}_{\mathrm{B}}(\mathrm{K})$ \\
\hline $\mathrm{Fe} @ \mathrm{SiO}_{2}$ & 173.134 & 19.232 & 302.564 & 113.909 \\
\hline $\mathrm{Fe} @ \mathrm{SiO}_{2} / \mathrm{Pe}$ & 119.482 & 17.333 & 338.573 & 117.127 \\
\hline
\end{tabular}

\subsection{Biomarker peptide binds to $\mathrm{Fe} @ \mathrm{SiO}_{2}$ nanoparticles}

To determine the binding of the biomarker peptide to the $\mathrm{Fe} @ \mathrm{SiO}_{2}$ nanoparticles, we used a biotinylated peptide and a streptavidin-HRP system to detect the functionalization (Figure 9). The non-functionalized $\mathrm{Fe} @ \mathrm{SiO}_{2}$, nanoparticles and the control displayed similar absorbance levels indicating that $\mathrm{Fe} @ \mathrm{SiO}_{2}$ nanoparticles would not contribute significantly to the absorbance obtained in the conjugate. In contrast, the functionalized $\mathrm{Fe} @ \mathrm{SiO}_{2}$ nanoparticles showed a significant increase in the absorbance levels in comparison with the control $(\mathrm{p}=0.0004)$, the biotinylated peptide $(\mathrm{p}=0.0010)$, and the nonfunctionalized $\mathrm{Fe} @ \mathrm{SiO}_{2}$ nanoparticles $(\mathrm{p}=0.0004)$. Although the absorbance of the biotinylated peptide indicates a nonspecific binding on the plate's surface, the absorbance of the nanoparticle conjugated with the peptide evidence the binding between both components in a significant way. Indeed, the absorbance of the conjugate exceeds four times the value observed for the nonfunctionalized $\mathrm{Fe} @ \mathrm{SiO}_{2}$ nanoparticle (Figure 9).

Surface-Functionalized metal Fe@ $\mathrm{SiO}_{2}$ has been widely used for biomedical applications ${ }^{39}$. Fe@ $\mathrm{SiO}_{2}$ nanoparticles

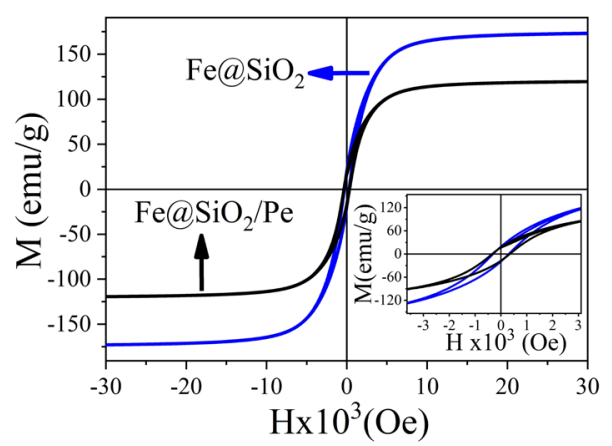

Figure 8. Room temperature, magnetic hysteresis loops of $\mathrm{Fe} @ \mathrm{SiO}_{2}$, and $\mathrm{Fe} @ \mathrm{SiO}_{2} / \mathrm{Pe}$. Inset: Extended hysteresis loops.

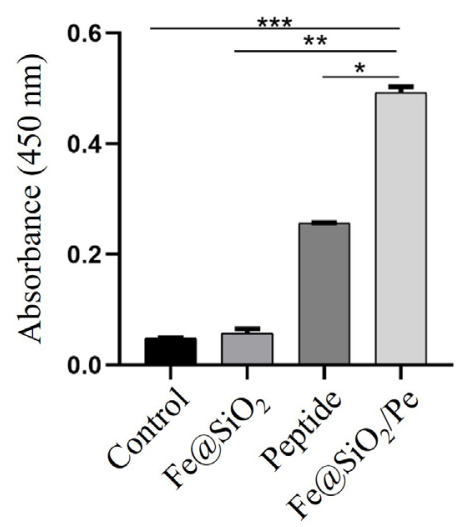

Figure 9. Detection of functionalization of $\mathrm{Fe} @ \mathrm{SiO}_{2}$ nanoparticles with the biomarker peptide. The binding of the peptide to the Fe@ $\mathrm{SiO}_{2}$ nanoparticles was detected through a biotin-streptavidin-HRP system. Data are expressed as normalized values \pm SEM $(n=2)$. Statistical differences were determined by Student's $t$ test: ${ }^{*} p=0.0010$, ** $p=0.0004$ and $* * * p=0.0004$. 
conjugated with biomarkers could be used to detect molecular changes under pathological conditions or for controlled drug loading/releasing. These nanoparticles were conjugated with a peptide biomarker to detect alterations in the brain parenchyma, specifically to the $\mathrm{BBB}$ under neuroinflammatory conditions. In this work, $\mathrm{Fe} @ \mathrm{SiO}_{2} / \mathrm{Pe}$ nanoparticles was proposed as potential candidates to be used as MRI contrast agents for their outstanding magnetic properties $^{40}$ and the biocompatible-coating of nZVI could make them potential candidates for biomedical application ${ }^{41}$. Nevertheless, additional studies are required to confirm $\mathrm{Fe} @ \mathrm{SiO}_{2} / \mathrm{Pe}$ nanoparticle's effectiveness in the detection of neuroinflammatory alterations under in vivo models.

\section{Conclusion}

The synthesis, structural, morphological, chemical and magnetic characterization of the $\mathrm{Fe} @ \mathrm{SiO}_{2}$ and $\mathrm{Fe} @ \mathrm{SiO}_{2} / \mathrm{Pe}$ nanoparticles was made, and allowed determine a size of $54 \pm 10 \mathrm{~nm}$ with low polydispersity, spherical in shape, with crystalline phases favoring their superparamagnetic properties. The silica coating of the nanoparticles generates an increase in size and a minimum shielding of the magnetic properties preventing further oxidation of the nZVI. The peptide was effectively conjugated with the superparamagnetic nZVI highlighting its potential as specific contrast agent for diagnosis of neuroinflammatory pathologies by MRI.

\section{Acknowledgements}

This work has been funded by Minciencias grant No. 123377757091 (CT-672-2018), Vicerrectoría de Investigación (VCTI) from the Universidad Antonio Nariño grant No. 2017223 and 2019204 and the Universidad de los Andes FAPA project No P20.263622.005/01. The authors are grateful to Dr. William Chamorro for his comments on the manuscript.

\section{References}

1. Rueda AP, Enríquez LF. Una revisión de técnicas básicas de neuroimagen para el diagnóstico de enfermedades neurodegenerativas. Biosalud. 2018;17(2):59-90.

2. Lee DW, Fatima H, Kim KS. Preparation of silica coated magnetic nanoparticles for bioseparation. J Nanosci Nanotechnol. 2018;18(2):1414-8.

3. Daldrup-Link HE. Ten things you might not know about iron oxide nanoparticles. Radiology. 2017;284(3):616-29.

4. Khurshid H, Tzitzios V, Colak L, Fang F, Hadjipanayis GC. Metallic iron-based nanoparticles for biomedical applications. J Phys Conf Ser. 2010;200:072049.

5. Chung RJ, Shih HT. Preparation of multifunctional Fe@ Au core-shell nanoparticles with surface grafting as a potential treatment for magnetic hyperthermia. Materials. 2014;7(2):65361.

6. Miranda M, Bustamante L. Diagnóstico genético para enfermedades neurodegenerativas. un importante desafío para chile. Rev Med Clin Las Condes. 2016;27(3):332-7.

7. Xiao YD, Paudel R, Liu J, Ma C, Zhang ZS, Zhou SK. MRI contrast agents: classification and application. Int J Mol Med. 2016;38(5):1319-26.

8. Van Rooy I, Cakir-Tascioglu S, Couraud PO, Romero IA, Weksler $\mathrm{B}$, Storm $\mathrm{G}$, et al. Identification of peptide ligands for targeting to the blood-brain barrier. Pharm Res. 2010;27(4):673-82.
9. Kelly KA, Allport JR, Tsourkas A, Shinde-Patil VR, Josephson L, Weissleder R. Detection of vascular adhesion molecule-1 expression using a novel multimodal nanoparticle. Circ Res. 2005;96(3):327-36.

10. Xiao YD, Paudel R, Liu J, Ma C, Zhang ZS, Zhou SK. MRI contrast agents: classification and application. Int J Mol Med. 2016;38(5):1319-26

11. Song XR, Goswami N, Yang HH, Xie J. Functionalization of metal nanoclusters for biomedical applications. Analyst. 2016;141(11):3126-40.

12. Yang TI, Brown RNC, Kempel LC, Kofinas P. Controlled synthesis of core-shell iron-silica nanoparticles and their magnetodielectric properties in polymer composites. Nanotechnology. 2011;22(10):105601.

13. Zhang Z, Huihong L, Li X, Xiaomao L, Songlin R, Zhiyuan $\mathrm{C}$, et al. Conversion of $\mathrm{CaTi}_{1-\mathrm{x}} \mathrm{Mn}_{\mathrm{x}} \mathrm{O}_{3-\delta}$-based photocatalyst for photocatalytic reduction of NO via structure-reforming of ti-bearing blast furnace slag. ACS Sustain Chem\& Eng. 2019;7(12):10299-309.

14. Hsieh PW, Tseng CL, Kuo DH. Preparation of $\mathrm{SiO}_{2}$-protecting metallic Fe nanoparticle $/ \mathrm{SiO}_{2}$ composite spheres for biomedical application. Materials. 2015;8(11):7691-701.

15. Vargas-Sanchez K, Vekris A, Petry KG. DNA subtraction of in vivo selected phage repertoires for efficient peptide pathology biomarker identification in neuroinflammation multiple sclerosis model. Biomarker insights. 2016;11:19-29.

16. Calero MC. Caracterización de nanopartículas magnéticas en cultivos celulares para sus aplicaciones biomédicas [dissertation]. Madrid: Universidad Autónoma de Madrid; 2015.

17. Luo B, Song XJ, Zhang F, Xia A, Yang WL, Hu JH, et al. Multi-functional thermosensitive composite microspheres with high magnetic susceptibility based on magnetite colloidal nanoparticle clusters. Langmuir. 2010;26(3):1674-9.

18. Rojas HA, Martínez JJ, Vargas AY. Selección de soportes magnéticos para la inmovilización de Ureasa. Ingeniería y Competitividad. 2014;16(2):289-96.

19. Zhu S, Shimokawa S, Shoyama Y, Tanaka H. A novel analytical ELISA-based methodology for pharmacologically active saikosaponins. Fitoterapia. 2006;77(2):100-8.

20. Lee HY, Atlasevich N, Granzotto C, Schultz J, Loike J, Arslanoglu J. Development and application of an ELISA method for the analysis of protein-based binding media of artworks. Anal Methods. 2015;7(1):187-96.

21. Hu P, Kang L, Chang T, Yang F, Wang H, Zhang Y, et al. High saturation magnetization $\mathrm{Fe}_{3} \mathrm{O}_{4}$ nanoparticles prepared by one-step reduction method in autoclave. J Alloys Compd. 2017;728:88-92.

22. Eglal MM, Ramamurthy AS. Nanofer ZVI: morphology, particle characteristics, kinetics, and applications. J Nanomater. 2014;2014(29):29

23. Maldonado-Camargo L, Unni M, Rinaldi C. Magnetic characterization of iron oxide nanoparticles for biomedical applications. In Petrosko S, Day E, editors. Biomedical Nanotechnology. Methods in Molecular Biology. New York: Humana Press; 2017. P. 47-71.

24. Mirlohi S. In vitro evaluation of iron-induced salivary lipid oxidation associated with exposure to iron nanoparticles: application possibilities and limitations for food and exposure sciences. Int J Environ Res Public Health. 2020;17(10):3622.

25. Babić-Stojić B, Jokanović V, Milivojević D, Požek M, Jagličić Z, Makovec D, et al. Ultrasmall iron oxide nanoparticles: magnetic and NMR relaxometric properties. Curr Appl Phys. 2018;18(2):141-9.

26. Kreuter J, Ramge P, Petrov V, Hamm S, Gelperina SE, Engelhardt $\mathrm{B}$, et al. Direct evidence that polysorbate-80-coated poly (butylcyanoacrylate) nanoparticles deliver drugs to the CNS via specific mechanisms requiring prior binding of drug to the nanoparticles. Pharm Res. 2003;20(3):409-16. 
27. Chaurasia AK, Thorat ND, Tandon A, Kim J, Park SH, Kim KK. Coupling of radiofrequency with magnetic nanoparticles treatment as an alternative physical antibacterial strategy against multiple drug resistant bacteria. Sci Rep. 2016;6:1-13.

28. Hajarul AAW, Razak KA, Zakaria ND. Properties of amorphous silica nanoparticles colloid drug delivery system synthesized using the micelle formation method. J Nanopart Res. 2014;16(2):1-14.

29. Balakrishnan V, Hajarul AAW, Razak KA, Shamsuddin S. In vitro evaluation of cytotoxicity of colloidal amorphous silica nanoparticles designed for drug delivery on human cell lines. J Nanomater. 2013;2013:1-9.

30. Danaei M, Dehghankhold M, Ataei S, Hasanzadeh Davarani F, Javanmard R, Dokhani A, et al. Impact of particle size and polydispersity index on the clinical applications of lipidic nanocarrier systems. Pharmaceutics. 2018;10(2):57.

31. Shao H, Qi J, Lin T, Zhou Y. Preparation and characterization of Fe3O4@SiO2@NMDP core-shell structure composite magnetic nanoparticles. Ceram Int. 2018;44(2):2255-60.

32. Zhang M, Liu Q. Solvothermal synthesis and magnetic properties of monodisperse $\mathrm{Ni}_{0.5} \mathrm{Zn}_{0.5} \mathrm{Fe}_{2} \mathrm{O}_{4}$ hollow nanospheres. High-Temp Mater Process. 2019;38:76-83.

33. Liu X, Wu N, Zhou P, Bi N, Or SW, Cui C, et al. Large scale synthesis of superparamagnetic face-centered cubic $\mathrm{Co} / \mathrm{C}$ nanocapsules by a facile hydrothermal method and their microwave absorbing properties. Mater Res. 2015;18(4):756-62.
34. Suzuki M, Fullem SI, Suzuki IS, Wang L, Zhong CJ. Observation of superspin-glass behavior in $\mathrm{Fe}_{3} \mathrm{O}_{4}$ nanoparticles. Phys $\mathrm{Rev}$ B. 2009;79(2):024418.

35. Jaber H, Kovacs T. Selective laser melting of Ti alloys and hydroxyapatite for tissue engineering: progress and challenges. Mater Res Express. 2019;6(8):082003.

36. Doltra A, Stawowy P, Dietrich T, Schneeweis C, Fleck E, Kelle $\mathrm{S}$. Magnetic resonance imaging of cardiovascular fibrosis and inflammation: from clinical practice to animal studies and back. BioMed Res Int. 2013;2013:676489.

37. Li M, Chen X, Guan J, Wang X, Wang J, Williams CT, et al. A facile and novel approach to magnetic Fe@SiO2 and FeSi2@ SiO2 nanoparticles. J Mater Chem. 2012;22(2):609-16.

38. Le Z, Huiping S, Hang Z, Xiangyuan R. Synthesis and Characterization of Fe3O4@SiO2 magnetic composite microspheres. Rare Met Mater Eng. 2018;47(2):594-9.

39. Liu S, Han M. Silica-coated metal nanoparticles. Chem Asian J. 2010;5(1):36-45.

40. DallaVecchia E, Coisson M, Appino C, Vinai F, Sethi R. Magnetic characterization and interaction modeling of zerovalent iron nanoparticles for the remediation of contaminated aquifers. $\mathrm{J}$ Nanosci Nanotechnol. 2009;9(5):3210-8.

41. Chung R, Shih H. Preparation of multifunctional Fe@Au coreshell nanoparticles with surface grafting as a potential treatment for magnetic hyperthermia. Materials. 2014;7(2):653-61. 